\title{
Study on Fatigue Lifetimes and Their Variation of Mg Alloy AZ61 at Various Stress Ratios
}

\author{
Kenichi Masuda ${ }^{1}$, Sotomi Ishihara ${ }^{1,2}$, Minoru Ishiguro², Hiroshi Shibata ${ }^{2}$ \\ ${ }^{1}$ Department of Mechanical Engineering, University of Toyama, Toyama, Japan \\ ${ }^{2}$ National Institute of Technology, Toyama College, Toyama, Japan \\ Email:masuda@eng.u-toyama.ac.jp
}

How to cite this paper: Masuda, K., Ishihara, S., Ishiguro, M. and Shibata, H. (2018) Study on Fatigue Lifetimes and Their Variation of Mg Alloy AZ61 at Various Stress Ratios. Materials Sciences and Applications, 9, 993-1007.

https://doi.org/10.4236/msa.2018.913072

Received: October 23, 2018

Accepted: November 30, 2018

Published: December 3, 2018

Copyright $\odot 2018$ by authors and Scientific Research Publishing Inc. This work is licensed under the Creative Commons Attribution International License (CC BY 4.0).

http://creativecommons.org/licenses/by/4.0/

\begin{abstract}
In this study, fatigue tests under different $R$ ratios were conducted on the AZ61 Mg alloy to investigate its fatigue lifetimes and fatigue crack growth (FCG) behavior. The fracture surface of the failed specimens was investigated using a scanning electron microscope to study the size of the intermetallic compounds from which the pioneer fatigue crack initiated and led to the final failure of the specimen. To determine the maximum size of the intermetallic compounds existing within the cross section of the specimen at higher risk, Gumbel's extreme-value statistics were utilized. In the present study, the intermetallic compounds contained within the specimen were assumed to be the initial cracks existing in the material before the fatigue tests. A modified linear elastic fracture-mechanics parameter, $M$, proposed by McEvily et al., was used to analyze the short FCG behavior under different stress ratios, $R$. The relation between the rate of FCG and $M$ parameter was found to be useful and appropriate for predicting the fatigue lifetimes under different $R$ ratios. Moreover, the probabilistic stress-fatigue life (P-S-N) curve of the material under different $R$ ratios could be predicted with this method, which utilizes both the FCG law and a statistical distribution of sizes of the most dangerous intermetallic compounds. The evaluated results were in good agreement with the experimental ones. This correspondence indicates that the estimation method proposed in the present study is effective for evaluation of the probabilistic stress-fatigue life (P-S-N) curve of the material under different $R$ ratios.
\end{abstract}

\section{Keywords}

Fatigue, Stress-Fatigue Life (S-N) Curve, Probabilistic Stress-Fatigue Life (P-S-N) Curve, Crack Growth, Extruded Magnesium Alloy, Intermetallic Compound, Extreme-Value Statistics 


\section{Introduction}

Magnesium alloys are attractive materials from the viewpoints of lightness, dimensional stability, cutting performance, specific strength, and recyclability. For these reasons, they are used in various industrial products, such as car components and structural materials. At present, the process of die-casting is widely used for these alloys. However, the use of extruded materials is increasing, and it is of importance to understand the fatigue performance of the extruded $\mathrm{Mg}$ alloys.

It is well known that defects and intermetallic compounds are contained in $\mathrm{Mg}$ alloys when they are processed. It is considered that these defects and intermetallic compounds strongly influence the statistical distribution of the fatigue lifetimes and fatigue crack growth (FCG) behavior. Several studies on the fatigue of extruded Mg alloys [1] [2] [3] [4] [5] have been performed. However, there are few studies on the distribution of the fatigue lifetimes of the extruded $\mathrm{Mg}$ alloys.

In this study, fatigue tests under different $\mathrm{R}$ ratios were conducted using an extruded $\mathrm{Mg}$ alloy to investigate the statistical distribution of fatigue lifetimes. Further, the FCG behavior of the material was also investigated. Then, the sizes of the intermetallic compounds, from which the main crack initiated and caused the final failure of the specimen, were investigated in detail by observations of the fractured surfaces of the specimens using a scanning electron microscope (SEM).

The statistical distribution of sizes of the most dangerous intermetallic compounds was investigated. For the data analysis, Gumbel's extreme-value statistics [6] were utilized. After that, the fatigue lifetimes under different $R$ ratios were evaluated using the $M$ parameter proposed by McEvily et al. [7]. Then, the probabilistic stress-fatigue life (P-S-N) curves of the material were estimated using the distribution of sizes of the intermetallic compound. The estimated results were in good agreement with the experimental ones.

\section{The Modified LEFM Approach for the Short FCG}

To evaluate the FCG behavior and stress-fatigue life (S-N) curve at different stress ratios, the modified linear elastic fracture mechanics (LEFM) method proposed by McEvily et al. [7] was used in the present study. The method will be explained briefly below.

The modified LEFM approach [7] is based upon the constitutive law expressed by

$$
\frac{\mathrm{d} a}{\mathrm{~d} N}=A\left(\Delta K_{\mathrm{eff}}-\Delta K_{\text {effth }}\right)^{2},
$$

where $A$ is a material constant; $\Delta K_{\text {eff }}$ is the range of the effective stress intensity factor and is defined as $K_{\max }$, the maximum stress intensity factor in a loading cycle, minus $K_{\mathrm{op}}$, the stress intensity factor at the crack-opening level; and $\Delta K_{\text {effth }}$ is the effective range of the stress intensity factor at the threshold level. 
The growth behavior of short fatigue cracks differs from the growth of large fatigue cracks in the following three important aspects.

\subsection{Elastic-Plastic Behavior}

Irwin [8] proposed that the linear-elastic approach could be extended to include the elastic-plastic behavior, i.e., those cases where the crack-tip plastic zone size is large with respect to the crack length, by increasing the actual crack length, a, by one-half of the plastic zone size. If the plastic zone size is assumed as that defined by Dugdale [9], then the modified crack growth length, $a_{\text {mod }}$, is given as

$$
a_{\text {mod }}=a+\frac{1}{2}\left(\sec \frac{\pi}{2} \frac{\sigma_{\max }}{\sigma_{Y}}-1\right) a=a F .
$$

where $\sigma_{\max }$ is the maximum stress in a loading cycle, $\sigma_{Y}$ is the yield strength, and $F$, the elastic-plastic correction factor, is given by

$$
F=\frac{1}{2}\left(\sec \frac{\pi}{2} \frac{\sigma_{\max }}{\sigma_{Y}}+1\right) \text {. }
$$

\subsection{Transient Crack Closure}

The level of crack closure developed in the wake of a crack varies from zero for a newly formed crack up to $K_{\text {opmax }}$ for a macroscopic crack. The following expression has been proposed [10] to describe this transient in crack closure behavior:

$$
\Delta K_{\text {op }}=\left(1-e^{-k \lambda}\right)\left(K_{\text {opmax }}-K_{\min }\right) \text {, }
$$

where $\Delta K_{\mathrm{op}}$ is the value of $K_{\mathrm{op}}-K_{\min }$ in the transient range; $k$ is a material constant (units $\mathrm{m}^{-1}$ ), which determines the rate of crack closure development; $\lambda$ is the length of the newly formed crack (units m); and $K_{\text {opmax }}$ is the magnitude of the crack opening level associated with completion of the transient period of growth. The value of $\lambda$ at the end of the transient period is generally less than a millimeter.

\subsection{Kitagawa Effect [11]}

In a very short crack range, the rate of crack growth is determined by the range of cyclic stress rather than the range of the stress intensity factor (Kitagawa effect [11]). To achieve a smooth transition from $\Delta K$ control of the rate of FCG for cracks of macroscopic size to $\Delta \sigma$ control for cracks of microscopic size (the Kitagawa effect [11]), the following driving force for FCG, $\Delta K$, is now generalized [12] [13] [14] to take into account geometries other than just the center-cracked panel as

$$
\Delta K=\left(\sqrt{2 \pi r_{e} F}+Y \sqrt{\pi a F}\right) \Delta \sigma
$$

where the value of $Y$ depends upon the crack shape. If it is assumed that the initial crack shape in an unnotched specimen is semi-circular, then the value of $Y$ is 0.73 [15].

The magnitude of $r_{\mathrm{e}}$ is of the order of $1 \mu \mathrm{m}$. Its value is determined by setting 
a equal to $r_{\mathrm{e}}, \Delta K$ equal to the effective range of the stress intensity factor at the threshold level, $\Delta K_{\text {effth }}\left(\mathrm{d} a / \mathrm{d} N=10^{-11} \mathrm{~m} /\right.$ cycle $)$, and $\Delta \sigma$ equal to the stress range at the fatigue strength level, $\Delta \sigma_{\mathrm{EL}}\left(10^{7}\right.$ cycles $)$, i.e.,

$$
r_{\mathrm{e}}=\frac{1}{4.5 \pi \mathrm{F}}\left(\frac{\Delta K_{\mathrm{effth}}}{\Delta \sigma_{\mathrm{EL}}}\right)^{2}
$$

In this modified approach, $r_{\mathrm{e}}$ is considered the effective length of an inherent flaw. In this interpretation of $r_{\mathrm{e}}$, a newly formed crack is only significant when its length exceeds $r_{\mathrm{e}}$, as for crack lengths less than $r_{\mathrm{e}}$ the stress intensity factor associated with $r_{\mathrm{e}}$ will be larger.

It is pointed out that there is no relationship between $r_{\mathrm{e}}$ and an actual defect, such as intermetallic compounds, in the actual material. It is merely an adjustable parameter introduced, as in the El Haddad, Topper and Smith's case [16], to deal with the Kitagawa effect [11] in a quantitative manner.

\subsection{A Generalized Expression for the Rate of FCG}

Considering these three aspects, i.e., the elastic-plastic behavior, crack closure, and Kitagawa effect, Equation (1) becomes

$$
\frac{\mathrm{d} a}{\mathrm{~d} N}=A\left[\left(\sqrt{2 \pi r_{\mathrm{e}} F}+Y \sqrt{\pi a F}\right) \Delta \sigma-\left(1-e^{-k \lambda}\right)\left(K_{\text {opmax }}-K_{\text {min }}\right)-\Delta K_{\text {effth }}\right]^{2}
$$

The use of Equation (6) requires that the following independent material constants be known or estimated: $A, \Delta \sigma_{\mathrm{EL}}, \sigma_{Y}, k, K_{o p \max }$, and $\Delta K_{\text {effth }}$.

Equation (6) can be expressed in a more compact form as

$$
\frac{\mathrm{d} a}{\mathrm{~d} N}=A M^{2},
$$

where $M$, the net driving force for FCG, is the quantity in brackets in Equation (6).

\section{Experimental Procedures and Materials}

\subsection{Materials and Specimens}

The material used was an extruded Mg alloy AZ61. Its chemical composition and mechanical properties are listed in Table 1 and Table 2, respectively. As can be seen in Table 1 , the present magnesium alloy contains $6 \% \mathrm{Al}, 0.6 \% \mathrm{Zn}$, and $0.4 \% \mathrm{Mn}$

For the fatigue tests in the present study, round bar specimens were used. Figure 1(a) shows the shape and dimensions of the specimen used. As can be seen from the figure, the specimen has a gauge diameter of $6 \mathrm{~mm}$ and a gripping

Table 1. Chemical composition of the material used (mass\%).

\begin{tabular}{cccccccc}
\hline $\mathrm{Al}$ & $\mathrm{Zn}$ & $\mathrm{Mn}$ & $\mathrm{Fe}$ & $\mathrm{Si}$ & $\mathrm{Cu}$ & $\mathrm{Ni}$ & $\mathrm{Mg}$ \\
\hline 6.03 & 0.57 & 0.38 & 0.002 & 0.008 & 0.0016 & 0.0005 & Bal. \\
\hline
\end{tabular}


Table 2. Mechanical properties of the material used.

\begin{tabular}{cccc}
\hline Tensile Strength & $0.2 \%$ Proof stress & Elongation & Vickers Hardness \\
\hline $312[\mathrm{MPa}]$ & $285[\mathrm{MPa}]$ & $18.3[\%]$ & 59.5 \\
\hline
\end{tabular}

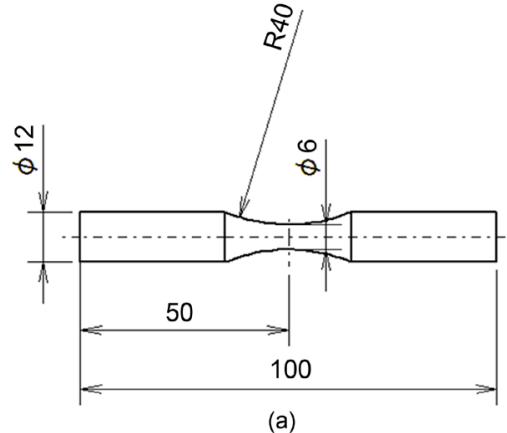

(a)

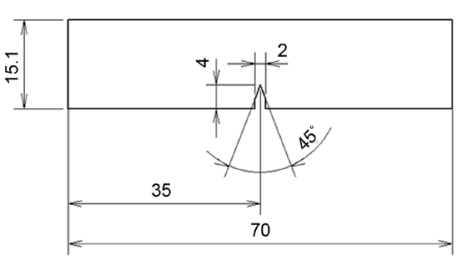

(b)

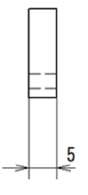

Figure 1. Shapes and dimensions of (a) round-bar specimens and (b) plate type specimens.

diameter of $12 \mathrm{~mm}$. For the measurement of the crack opening stress intensity factor, a single edge notched (SEN) specimen, as shown in Figure 1(b), was used. A strain gauge was attached at a point 1 to $2 \mathrm{~mm}$ in front of the crack tip, and the crack opening stress intensity factor, $K_{\mathrm{op}}$, was measured using the elastic compliance method that utilizes the relation of load-strain.

\subsection{Experimental Procedures}

\subsubsection{Fatigue Test}

To study the fatigue lifetimes and FCG behavior, two types of fatigue tests, the rotating bending fatigue test at stress ratio of $-1(R=-1)$ and push-pull fatigue test at $R=0.1$ and 0.5 , were conducted under laboratory air conditions. The fatigue tests at $R=-1$ were carried out using the rotating bending fatigue test machine at $15 \mathrm{~Hz}$ using the round bar specimens (Figure 1(a)).

The push-pull fatigue tests were conducted using a servo-hydraulic fatigue-testing machine at $15 \mathrm{~Hz}$. The replica method was employed to investigate the short FCG behavior. The fatigue tests were periodically interrupted at a constant interval during the fatigue process to obtain replicas of the specimen surfaces. The crack lengths recorded on the replicas were observed with an optical microscope with a magnification of 200. For a calculation of the stress intensity factor, $K$, for the surface fatigue crack, the following expression was used:

$$
K=Y \sigma \sqrt{\pi a},
$$

where $\sigma$ is the applied stress amplitude, $a$ is the half crack length, and $Y$ is a crack-shape correction factor. A value of 0.73 for $Y$ was used, assuming that the crack-shape is semi-circular.

\subsubsection{Through Thickness FCG Behavior}

To study the FCG behavior of the through thickness fatigue crack, three-point bending fatigue tests were conducted at $R=0.1$ and at a frequency of $15 \mathrm{~Hz}$, us- 
ing the servo-hydraulic fatigue testing machine. The notched specimen, as shown in Figure 1(b), was used for the fatigue tests. The tests were conducted in laboratory air at room temperature. The crack lengths were measured using the replica method. For a calculation of the stress intensity factor, $K$, the following expression was used [17].

$$
\begin{gathered}
K=\frac{3 S P}{2 t W^{2}} \sqrt{\pi a} \cdot F(\alpha), \quad \alpha=\frac{a}{W}, \\
F(\alpha)=\frac{1.99-\alpha(1-\alpha)\left(2.15-3.93 \alpha+2.7 \alpha^{2}\right)}{(1+2 \alpha)(1-\alpha)^{3 / 2}}
\end{gathered}
$$

where $P$ is the applied load, $S$ is length of the supporting point, $t$ is specimen thickness, $W$ is specimen width, and $a$ is the crack length. The crack opening stress-intensity factor, $K_{\text {op }}$, during a loading cycle was determined by affixing strain gauges ahead of the crack tip. At that time, the elastic compliance method [18] was used.

\subsubsection{Statistical Distribution of the Sizes of the Compounds}

To clarify the crack initiation sites in the eight fatigue-fractured specimens, the fracture surfaces of these specimens were examined using an SEM. It was found that the pioneer crack that caused the final failure of the specimen was initiated from the intermetallic compounds contained in the specimen. This result was common to the eight test pieces. Then, the sizes (areas) of the intermetallic compounds were measured for each specimen. The statistical distribution of the areas of the intermetallic compounds was utilized for estimation of the P-S-N curves of the Mg alloy used. To do this, the square roots of the areas of the crack initiation sites were plotted on a Gumbel's extreme probability paper.

\section{Experimental Results and Discussion}

\subsection{S-N Curves}

Figure 2 shows $\mathrm{S}-\mathrm{N}$ curves for the three different stress ratios, $R=-1,0.1$, and 0.5 . The data attached with the arrows in this figure indicate that, up to the plotted number of cycles, the specimen was not yet broken. For the stress ratio $R=-1$, the statistical distributions of fatigue lives are also shown in Figure 2. The statistical fatigue tests were conducted at three stress amplitudes, $180 \mathrm{MPa}, 170 \mathrm{MPa}$, and $160 \mathrm{MPa}$, using fifteen to twenty specimens for each of them. As seen in the figure, the stress amplitude, $\sigma_{a}$, at constant fatigue lives, such as $10^{5}$ and $10^{6}$ cycles, increases with a decrease in the values of $R$, from 0.5 to -1 . For $R=-1$, the range of data variation at the high stress amplitudes, 180 and $170 \mathrm{MPa}$, is almost the same. However, at a lower stress amplitude of $160 \mathrm{MPa}$, the extent of variation in fatigue life becomes larger.

Figure 3 shows optical-microscope images of specimen surfaces that were fatigued at a constant stress amplitude of $170 \mathrm{MPa}$. As can be seen in these photographs, many black spots are distributed on the specimen surface. Using an electron 


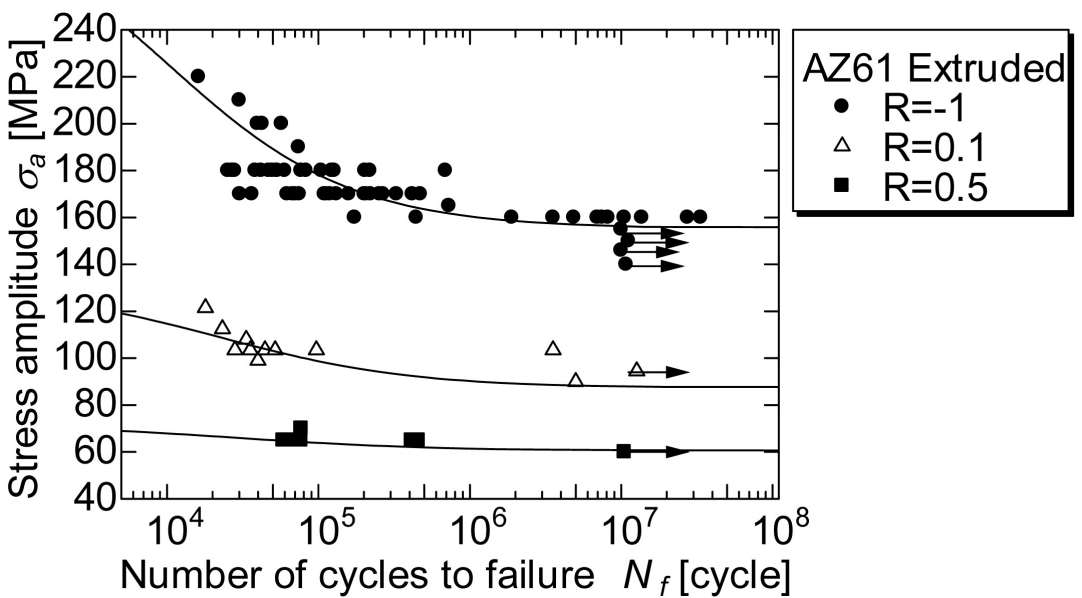

Figure 2. Relationship between $\sigma_{\mathrm{a}}$ and $N_{f}$ for three levels of $R$ with drawing fitting curves by least-square method.

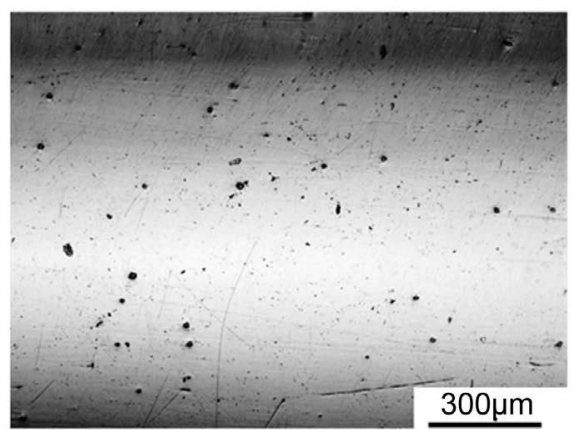

(a)

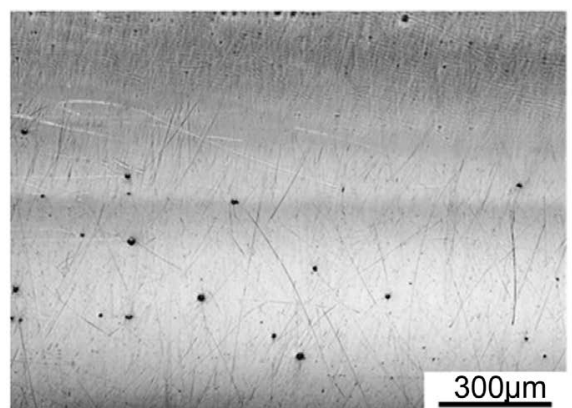

(c)

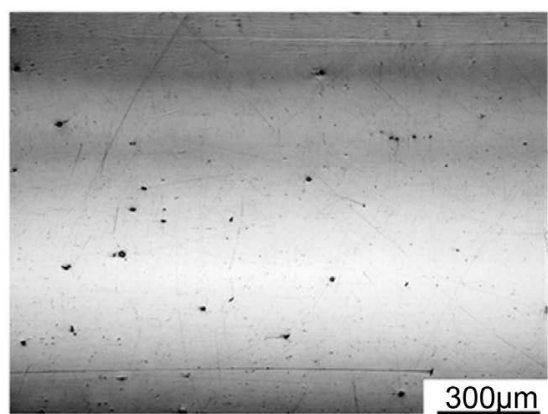

(b)

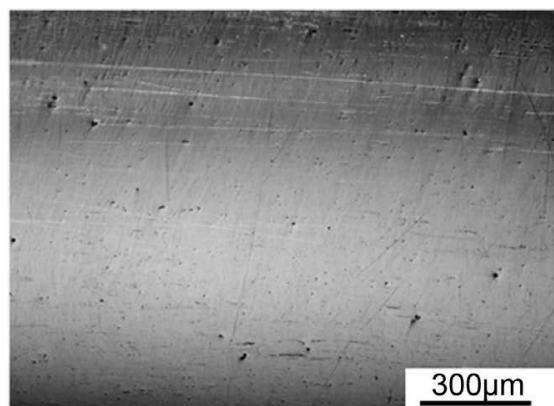

(d)

Figure 3. Examples of the specimen surface showing existences of the many intermetallic compounds. (a) $N_{f}=23,840$; (b) $N_{f}=67,519 ;$ (c) $N_{f}=422,744$; (d) $N_{f}=1,428,495$.

probe micro-analyzer (EPMA), these black spots were identified as an intermetallic compound, Mn-Al. As shown in Figure 3, the fatigue lifetimes, $N_{f}$ increased with a decrease in the intermetallic compound density. This result indicates that the density of the intermetallic compound is a critical factor that controls the fatigue lifetime length.

In these fatigue tests, conducted at a constant stress amplitude of $170 \mathrm{MPa}$, the fatigue lifetime, $N_{f}$ for each of the specimens increased with a decrease in the number of intermetallic compounds contained in the specimen. 


\subsection{FCG Behavior}

To investigate crack initiation and FCG behavior, successive observations of the unnotched specimen surfaces during the fatigue process were conducted using the replica method. Figure 4 shows a typical FCG behavior, i.e., 2a vs. $N$ relation, of the specimen tested at stress amplitude of $165 \mathrm{MPa}$ and stress ratio of -1 $(R=-1)$. Here, $2 \mathrm{a}$ is the crack length and $N$ is the number of cycles of the repeated stress. The specimen failed at 49,496 cycles. The figure shows that the fatigue crack initiated at about $10 \%$ of the fatigue lifetime. This result means that the fatigue life $N_{f}$ can be approximated by the crack growth life $N_{p}$, neglecting the crack initiation life $N_{i}$. The same trends were also confirmed in other similar tests.

Figure 5 shows the fracture surface of the specimen fatigue fractured at stress amplitude of $\sigma_{a}=160 \mathrm{MPa}$ under stress ratio, $R=-1$. As can be seen in the figure, the fatigue crack initiated from the intermetallic compound ( $\mathrm{Mn}-\mathrm{Al}$ ), indicated by the white arrow. It can also be seen that the intermetallic compound existed just beneath the specimen surface. This finding was common with other observations.

\subsection{Statistical Distributions of Intermetallic Compounds Existing on the Fracture Surface of the Tested Specimen}

To investigate the size of intermetallic compounds at the crack initiation site of the specimen, the fracture surfaces of the eight specimens fatigued at the same stress amplitude were investigated using SEM. From the SEM observations, although the amount if experimental data is small, the projected area of the intermetallic compound of each sample was measured. Figure 6 shows the distribution of the square roots of the intermetallic compound areas observed at the fracture origins in the eight specimens. The data were plotted on an extreme-value probability paper [6]. The horizontal and vertical axes of this figure show the square

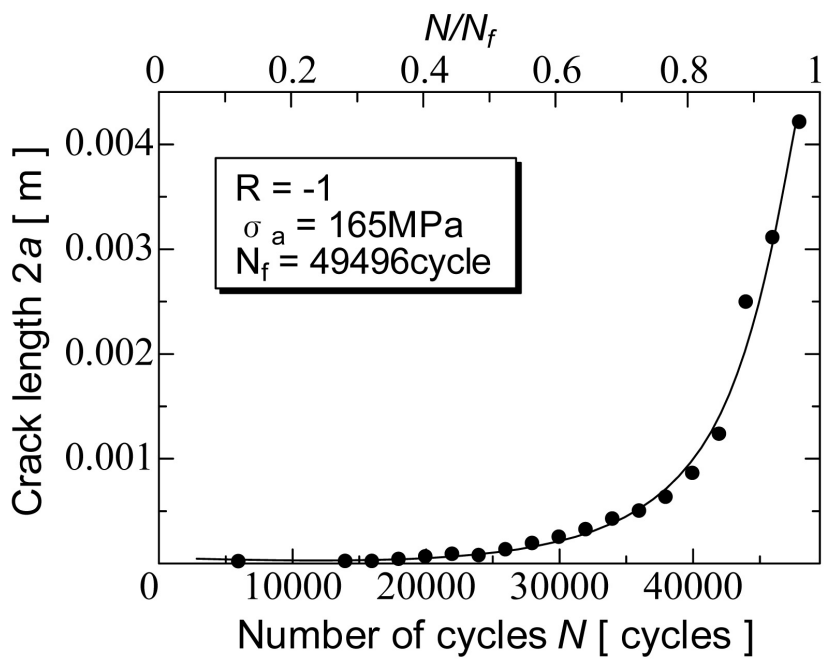

Figure 4. Relationship between $2 a$ and $N$ with $R=-1$ and $\sigma_{\mathrm{a}}=165 \mathrm{MPa}$. As seen in the figure, fatigue crack initiated at about $10 \%$ of the fatigue lifetime. 


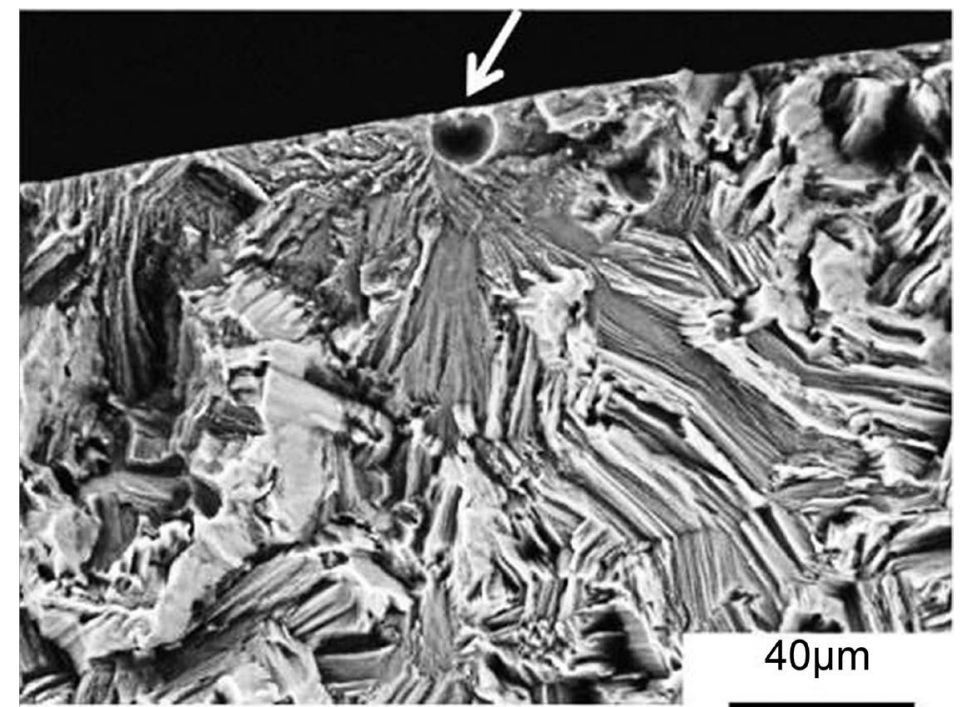

Figure 5. Fracture surface of the fatigued specimen $\left(\sigma_{\mathrm{a}}=160 \mathrm{MPa}, R=-1\right)$. As indicated by the white arrow in the figure, the fatigue crack initiated from the intermetallic compound, $\mathrm{Mn}-\mathrm{Al}$.

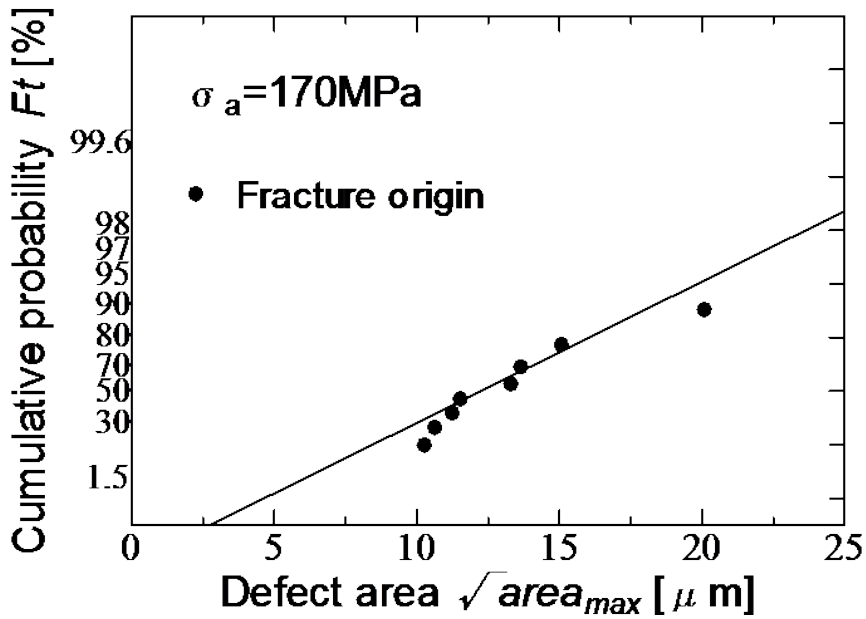

Figure 6. Extreme-value distribution of square root of the inclusion area at fracture origin.

roots of area, area ${ }^{1 / 2}$, and cumulative probability of area ${ }^{1 / 2}, F\left(\operatorname{area}^{1 / 2}\right)$, respectively. As can be seen, the experimental data are well approximated by the straight line drawn in the figure and are represented by the following double exponential function:

$$
F\left(\operatorname{area}_{\max }^{1 / 2}\right)=\exp \left[-\exp \left\{-\left(\frac{\operatorname{area}_{\max }^{1 / 2}-\gamma}{\alpha}\right)\right\}\right],
$$

where $F\left(\operatorname{area}_{\max }^{1 / 2}\right)$ indicates the cumulative probability of the square root of the area, area $^{1 / 2}$, of the intermetallic compound at the fracture origin, and $\alpha$ and $\gamma$ are material constants. Using the least-square method, the values of these constants, $\alpha$ and $\gamma$, were evaluated as 3.19 and 11.7, respectively. 


\section{Discussion}

\subsection{Derivation of S-N Curves Using the $M$ Parameter}

The value of $r_{\mathrm{e}}$ in Equation (6) is less than $1 \mu \mathrm{m}$, approximately. When cracks are generated from large intermetallic compounds having a diameter of $20 \mu \mathrm{m}$ or more, the length of the initial crack is longer than the value of $r_{\mathrm{e}}$. In such a situation, we can ignore the Kitagawa effect [11], and thus, the first term on the right side of Equation (6) can be deleted. Regarding the crack initiation mechanism, it is presumed that part of the interface between the intermetallic compound ( $\mathrm{Mn}-\mathrm{Al})$ and the matrix $\mathrm{Mg}$ is loosened or broken by interfacial sliding or stress concentration owing to the fatigue load, and the crack is generated from the interface.

A detailed study on the crack initiation mechanism will be needed in the future. In the following discussion, for simplicity, we assume that the largest intermetallic compound is equivalent to the pioneer crack causing the final failure of the specimen. That is, the diameter of the largest intermetallic compound is assumed to be equal to the initial crack length of the pioneer crack.

$$
\frac{\mathrm{d} a}{\mathrm{~d} N}=A\left[Y \Delta \sigma \sqrt{\pi a F}-\left(1-e^{-k a}\right)\left(K_{\text {op } \max }-K_{\min }\right)-\Delta K_{\text {effth }}\right]^{2}=A M^{2}
$$

Figure 7 shows the log-log plot of the relation between the rate of fatigue crack propagation $\mathrm{d} a / \mathrm{d} N$ and the modified linear elastic fracture-mechanics parameter $M$. The values of the parameters used for calculation of $M$ can be derived from Figure 8 by using the through crack as discussed in 3.2.2 Section. The values of the parameters are listed in Table 3. In Figure 7, the data for the short surface fatigue crack obtained from the rotating bending fatigue tests $(R=$ $-1)$ are plotted. In addition, the FCG data for the through thickness fatigue crack at $R=0.1$ are also plotted in the figure.

As seen in the figure, the rate of FCG, $\mathrm{d} a / \mathrm{d} N$, for both the surface crack and through thickness cracks can be expressed by using the $M$ parameter (solid line in Figure 7). Therefore, the relationship between $\mathrm{d} a / \mathrm{d} N$ and $M$ of the extruded Mg alloy can be expressed by Equation (12).

$$
\frac{\mathrm{d} a}{\mathrm{~d} N}=9.0 \times 10^{-9} M^{2} .
$$

It is possible to regard the FCG life, $N_{g}$, as equal to fatigue lifetimes, $N_{f}$ as the fatigue crack initiates early in the fatigue process. FCG life can be estimated by numerically integrating Equation (12), from an initial crack length $\left(a_{i}\right)$ to the critical crack length $\left(a_{c}\right)$.

$$
N_{f}=N_{g}=\int_{a_{i}}^{a_{c}} 1 /\left(9.0 \times 10^{-9} M^{2}\right) \mathrm{d} a
$$

Table 3. Parameters used for the calculation.

\begin{tabular}{cccc}
\hline$K_{\text {opmax }}$ & $K_{\text {effth }}$ & $\sigma_{y}$ & $k$ \\
\hline $2.0\left[\mathrm{MPam}^{1 / 2}\right]$ & $0.6\left[\mathrm{MPam}^{1 / 2}\right]$ & $285[\mathrm{MPa}]$ & $16000\left[\mathrm{~m}^{-1}\right]$ \\
\hline
\end{tabular}




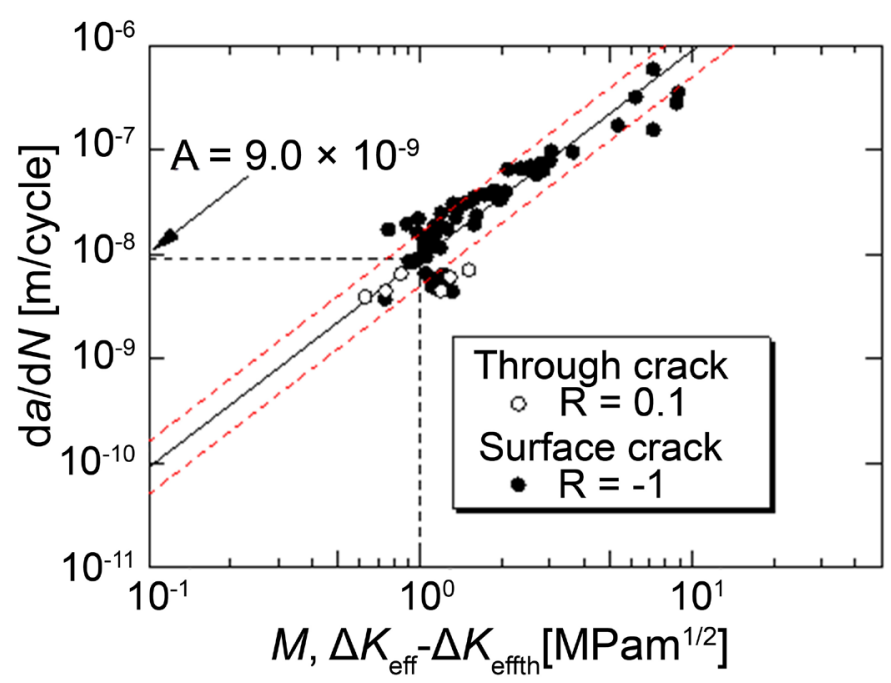

Figure 7. Log-log plot between $\mathrm{d} a / \mathrm{d} N$ and $M$ parameter for the short surface crack, and da/d $N$ vs. $\Delta K_{\text {eff }}-\Delta K_{\text {effth }}$ for the through crack.

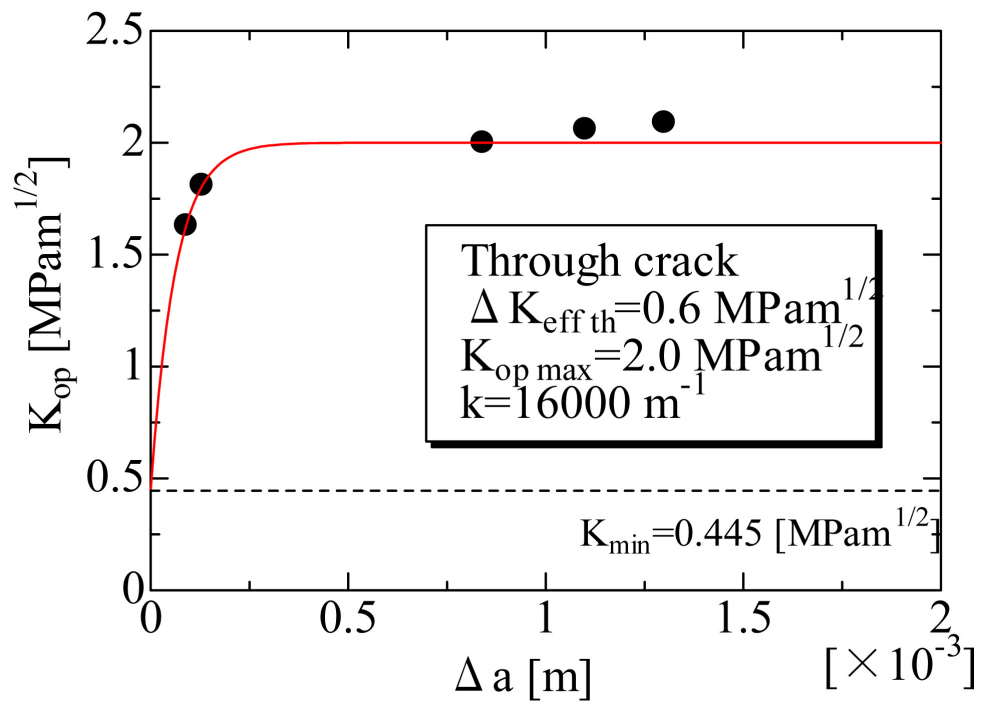

Figure 8. Relation of fatigue crack length $\Delta a$ and $K_{\mathrm{op}}$ for through crack by plate type specimen.

with the assumption that crack size is equivalent to diameter of the intermetallic compound, an initial crack length, $a_{p}$ can be determined by using the extreme-value of maximum area of the intermetallic compound. In the present study, to evaluate the S-N curves, the average intermetallic-compound diameter, $14.5 \mu \mathrm{m}$, was used as the value of $2 a_{i}$. The critical crack length, $a_{\mathcal{C}}$ should be determined from the value of the fatigue fracture toughness. However, for the sake of simplicity, in this study, a constant value of $4 \mathrm{~mm}$ was used regardless of stress amplitude. Figure 9 shows the comparison between the experimental data and calculation results. As can be seen in the figure, the calculated S-N curves for the three $R$ values are in good agreement with the experimental values, except for $R$ $=0.1$. 


\subsection{Evaluation of the P-S-N Curve}

The fatigue failures of the present $\mathrm{Mg}$ alloy specimens were caused by the crack that initiated from the most dangerous intermetallic compound in the specimen. Thus, the distribution of square root of the area of the intermetallic compound shown in Figure 6 was used for estimation of the P-S-N curve of the material. The square roots of the area of the intermetallic compound, with different values of cumulative probability such as $0.01,0.5,0.99$, were determined from Figure 6 and Equation (10). These values of area ${ }^{1 / 2}$ and of the corresponding diameters for different values of cumulative probability are listed in Table 4.

The estimated P-S-N curves are shown by the blue solid curves in Figure 10. Here, $P\left(N_{p}\right)=0.01, P\left(N_{p}\right)=0.5$, and $P\left(N_{p}\right)=0.99$ indicate the cumulative probabilities of fatigue failure of the material, respectively. In the figure, the experimental fatigue data are also shown for a comparison purpose. From this figure, relatively good agreement can be seen between the estimated P-S-N curves and experimental data. Therefore, the distribution of the square roots of the maximum intermetallic-compound areas is convenient and useful for evaluation of the distribution of the alloy fatigue lifetimes.

In the present study, the distribution of fatigue lifetimes of the extruded $\mathrm{Mg}$ alloy was derived considering only the statistical distribution of the sizes of intermetallic compounds existing at the crack initiation site. To predict a more

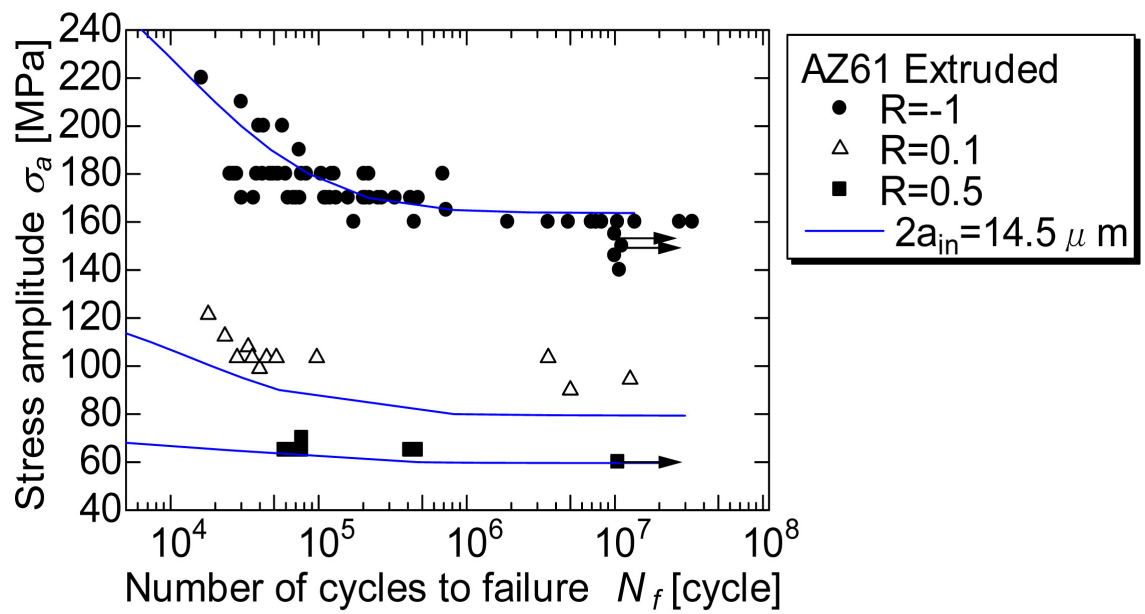

Figure 9. Comparison of S-N curves between experimental and numerical results for three levels of $R$.

Table 4. Square roots of the area, area ${ }^{1 / 2}$, of the intermetallic compound for several values of cumulative probability. These values were determined from the distribution of the extreme-value of square roots of the areas of the intermetallic compound at the fracture origin shown in Figure 6 and Equation (10).

\begin{tabular}{cccc}
\hline Cumulative probability (\%) $F\left(\mathrm{area}^{1 / 2}\right)$ & 1 & 50 & 90 \\
\hline Square root of the area of the intermetallic compound & $6.83 \mu \mathrm{m}$ & $12.9 \mu \mathrm{m}$ & $26.4 \mu \mathrm{m}$ \\
Diameter of the intermetallic compound & $7.70 \mu \mathrm{m}$ & $14.5 \mu \mathrm{m}$ & $29.8 \mu \mathrm{m}$ \\
\hline
\end{tabular}




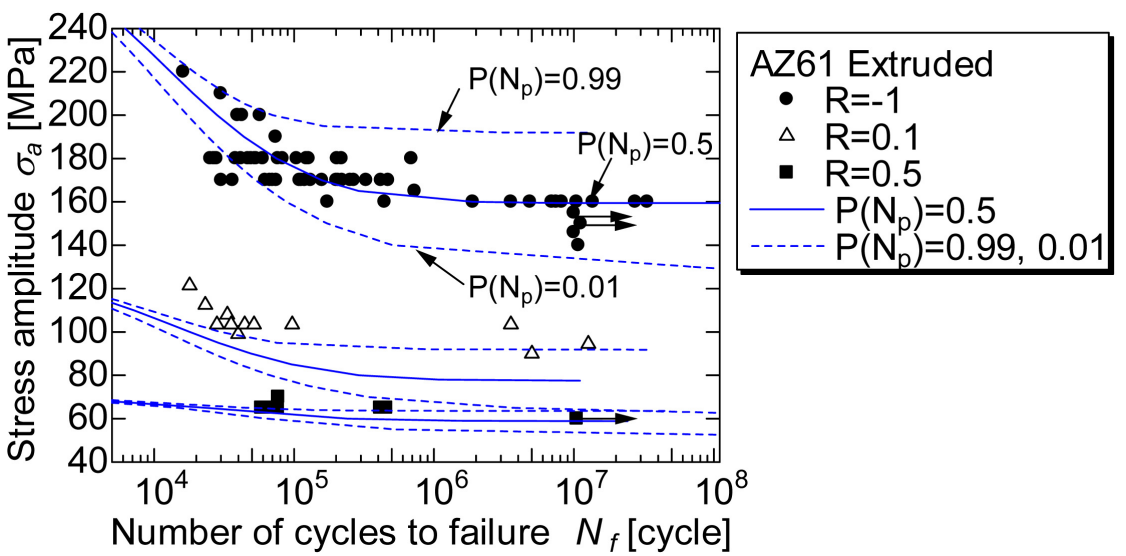

Figure 10. P-S-N curves at different $R$ ratios, $-1,0.1,0.5$. The experimental results also plotted in the figure for a comparison purpose.

accurate distribution of fatigue lifetimes, it is also necessary to consider the statistical variations in crack growth life.

In addition, for the sake of simplicity, the distribution of fatigue life was estimated by using the area distribution of intermetallic compounds at a small number of crack-occurrence sites under a constant stress amplitude. However, to obtain a more accurate fatigue life distribution, it is necessary to measure the area of more intermetallic compounds.

\section{Conclusions}

In the present study, the fatigue lifetimes and distributions of the fatigue lifetimes of an extruded $\mathrm{Mg}$ alloy were investigated at different stress ratios. Then, the intermetallic compounds contained within the specimen were assumed to be the initial cracks existing in the material before the fatigue tests. A modified linear elastic fracture-mechanics parameter, $M$, proposed by McEvily et al. [7], was used to analyze the short FCG behavior under different stress ratios, R. Moreover, the probabilistic stress-fatigue life (P-S-N) curve of the material under different $R$ ratios could be predicted with this method, which utilizes both the FCG law and a statistical distribution of sizes of the most dangerous intermetallic compounds. It follows that the following conclusions were obtained through the present study.

1) The stress amplitude, $\sigma_{a}$, at constant fatigue lives increased with a decrease in the values of $R$, from 0.5 to -1 . For $R=-1$; at high stress amplitudes of 180 and $170 \mathrm{MPa}$, the ranges of data variation for the fatigue lifetimes were almost the same. However, at a lower stress amplitude of $160 \mathrm{MPa}$, the extent of data variation for the fatigue lifetimes became larger than that at higher stress amplitudes, 180 and $170 \mathrm{MPa}$.

2) Many intermetallic compounds ( $\mathrm{Mn}-\mathrm{Al})$ were contained in the extruded Mg alloy AZ61. The fatigue lifetimes of the Mg alloy AZ61 increased with a decrease in the density of intermetallic compounds. This result indicates that the density of intermetallic compounds is a critical factor that controls the fati- 
gue-lifetime length.

3) The modified linear elastic fracture-mechanics parameter $M$, proposed by McEvily et al., was found to be effective to analyze the short FCG behavior of the extruded Mg alloy AZ61. The S-N diagrams at different stress ratios estimated by using the $M$ parameter were in good agreement with the experimental results.

4) For evaluation of the distribution of fatigue lifetimes, the distribution of the extreme-value for the square root of the area of the intermetallic compound and the relation, $\mathrm{d} a / \mathrm{d} N$ vs. $M$, were used. Good agreement was confirmed between the experimental and calculated results.

\section{Conflicts of Interest}

The authors declare no conflicts of interest regarding the publication of this paper.

\section{References}

[1] Zheng, S.L., Yu, Q. and Jiang, Y.Y. (2013) An Experimental Study of Fatigue Crack Propagation in Extruded AZ31B Magnesium Alloy. International Journal of Fatigue, 47, 174-183. https://doi.org/10.1016/j.ijfatigue.2012.08.010

[2] Bernard, J.D., Jordon, J.B., Lugo, M., Hughes, J.M., Raybom, D.C. and Horstemeyer, M.F. (2013) Observations and Modeling of the Small Fatigue Crack Behavior of an Extruded AZ61 Magnesium Alloy. International Journal of Fatigue, 52, 20-29. https://doi.org/10.1016/j.ijfatigue.2013.02.015

[3] Castro, F. and Jiang, Y.Y. (2016) Fatigue Life and Early Cracking Predictions of Extruded AZ31B Magnesium Alloy Using Critical Plane Approaches. International Journal of Fatigue, 88, 236-246. https://doi.org/10.1016/j.ijfatigue.2016.04.002

[4] Wang, C., Luo, T.J., Zhou, J.X. and Tang, Y.S. (2017) Anisotropic Cyclic Deformation Behavior of Extruded ZA81M Magnesium Alloy. International Journal of Fatigue, 96, 178-184. https://doi.org/10.1016/j.ijfatigue.2016.11.020

[5] Jordon, J.B., Brown, H.R., Kadiri, H.E., Kistler, H.M., Lett, R.L., Baird, J.C. and Luo, A.A. (2013) Investigation of Fatigue Anisotropy in an Extruded Magnesium Alloy. International Journal of Fatigue, 51, 8-14. https://doi.org/10.1016/j.ijfatigue.2013.01.006

[6] Gumbel, E.J. (1958) Statistics of Extremes. Columbia University Press, New York.

[7] McEvily, A.J., Eifler, D. and Macherauch, E. (1991) An Analysis of the Growth of Short Fatigue Cracks. Engineering Fracture Mechanics, 40, 571-584. https://doi.org/10.1016/0013-7944(91)90151-P

[8] Irwin, G.R. (1958) Fracture, Elasticity and Plasticity. Springer, Berlin, 551-590.

[9] Dugdale, D.S. (1960) Yielding of Steel Sheets Containing Slits. Journal of the Mechanics and Physics of Solids, 8, 100-104. https://doi.org/10.1016/0022-5096(60)90013-2

[10] McEvily, A.J. and Minakawa, K. (1984) Crack Closure and the Growth of Short and Long Fatigue Cracks. Department of Metallurgy, 18, 215-233.

https://doi.org/10.1016/0036-9748(84)90092-9

[11] Kitagawa, H. (1976) Applicability of Fracture Mechanics to Very Small Cracks or the Cracks in the Early Stage. Proceedings of 2nd ICM, Cleveland, 627-631.

[12] McEvily, A.J., Ishihara, S., Endo, M., Sakai, H. and Matsunaga, H. (2007) On One- 
and Two-Parameter Analyses of Short Fatigue crack Growth. International Journal of Fatigue, 29, 2237-2245. https://doi.org/10.1016/j.ijfatigue.2006.11.012

[13] McEvily, A.J., Ishihara, S. and Endo, M. (2005) An Analysis of Multiple Two-Step Fatigue Loading. International Journal of Fatigue, 27, 862-866.

https://doi.org/10.1016/j.ijfatigue.2005.04.001

[14] Ishihara, S., McEvily, A.J., Sato, M., Taniguchi, K. and Goshima, T. (2009) The Effect of Load Ratio on Fatigue Life and Crack Propagation Behavior of an Extruded Magnesium Alloy. International Journal of Fatigue, 31, 1788-1794. https://doi.org/10.1016/j.ijfatigue.2009.02.034

[15] Murakami, Y. (1993) Metal Fatigue: Effects of Small Defects and Nonmetallic Inclusions. Yokendo, Tokyo, 17.

[16] El Haddad, M.H., Topper, T.H. and Smith, K.N. (1979) Prediction of Non Propagating Cracks. Engineering Fracture Mechanics, 11, 573-584. https://doi.org/10.1016/0013-7944(79)90081-X

[17] ASTM (1990) Standard Test Method for Plane-Strain Fracture Toughness of Metallic Materials. E 399-90, Annual Book of ASTM Standards, Part 10.

[18] Kikukawa, M., Jono, M., Tanaka, K. and Takatani, M. (1976) Measurement of Fatigue Crack Propagation and Crack Closure at Low Stress Intensity Level by Unloading Elastic Compliance Method. Journal of the Society of Materials Science, Japan, 25, 899-903. (In Japanese) 